\title{
Turismo vivencial - presentación de actividades y su impacto en la vida de algunas comunidades andinas en Perú
}

\section{Olga Vilímková}

\section{(2) OpenEdition \\ Journals}

Edición electrónica

URL: http://journals.openedition.org/elohi/479

DOI: $10.4000 /$ elohi.479

ISSN: 2268-5243

Editor

Presses universitaires de Bordeaux

\section{Edición impresa}

Fecha de publicación: 1 enero 2015

Paginación: 75-100

ISBN: 979-10-300-0044-3

ISSN: 2431-8175

Referencia electrónica

Olga Vilímková, « Turismo vivencial - presentación de actividades y su impacto en la vida de algunas comunidades andinas en Perú », ELOHI [En línea], 7 | 2015, Publicado el 01 enero 2016, consultado el 19 abril 2019. URL : http://journals.openedition.org/elohi/479 ; DOI : 10.4000/elohi.479 


\section{Turismo vivencial - presentación de actividades y su impacto en la vida de algunas comunidades andinas en Perú}

\section{OLGA VILÍMKOVÁ \\ Fundación Inka - Univerzita Karlova v Praze (Praga)}

Durante los últimos años, en los Andes peruanos, se nota el crecimiento de la popularidad del turismo vivencial. El incremento de este fenómeno se debe al interés de todas las partes del turismo: comuneros autóctonos, turistas (tanto extranjeros como nacionales) y mediadores, es decir agencias turísticas.

En referencia al tema me interesa analizar cuáles son las experiencias de las comunidades andinas que realizan este tipo de turismo, si el turismo vivencial trae beneficios a los pobladores y cuáles son, y cuáles son los impactos negativos.

Primero, hablaré de las comunidades del departamento de Puno -del Lago Titicaca y de tierra firme-, y después de las del departamento de Cusco.

Como se trata de un tema actual, no hay estudios complejos sobre la problemática. Pero existen bastantes materiales publicados: artículos e informes sobre los proyectos de desarrollo en la zona rural, por ejemplo los de la Comisión de Promoción del Perú para la Exportación y el Turismo (PROMPERÚ ${ }^{1}$ ), o los del Centro de Estudios para el Desarrollo Regional (CEDER $\left.{ }^{2}\right)$, los materiales del proyecto «Capacitación en estándares de calidad y buenas prácticas de turismo sostenible», realizado por la Universidad Antonio Ruiz de Montoya (Lima) ${ }^{3}$ y otros análisis para las actividades de algunas ONGs.

1. La Comisión está adscrita al Ministerio de Comercio Exterior y Turismo, http:// www.promperu.gob.pe/, página consultada el 1.5.2015.

2. Se trata de una ONG. Véase http://ceder.org.pe/web/?p=52, página consultada el 1.5.2015. 3. María Eugenia de Aliaga, Rodrigo Cabrera Nieri, Omar Carbajal Barreda. Capacitación en estándares de calidad y buenas prácticas de turismo sostenible. Lima: Universidad Antonio Ruiz de Montoya / Asociación Odebrecht Perú, abril de 2011, 19 p., disponible en http://tinyurl. com/qjmfp7n, consulta del 1.5.2015. 
Según Aliaga, Cabrera y Carbajal, el turismo vivencial es una experiencia integral que promueve el contacto con culturas vivas, la interacción del poblador local con el viajero, el compartir costumbres, festividades y actividades cotidianas, cualesquiera que fueran, que enfatiza la actividad turística como intercambio cultural. Los autores diferencian el turismo vivencial del turismo participativo que definen como la experiencia de inter-aprendizaje y convivencia entre campesinos y turistas, donde se enfatizan de manera especial las actividades productivas cotidianas y tradicionales, y que aporta a las poblaciones locales, como resultado de dicha actividad turística, un beneficio económico directo. ${ }^{4}$

En el artículo presentaré informaciones que se basan en las experiencias personales de mis estancias en las comunidades andinas entre los años 1994 y 2014. En estos años, realicé más de 50 viajes a Perú. En 2001, trabajé un año como profesora voluntaria en la comunidad andina Pucamarca, distrito Chinchero, departamento de Cusco. Otros viajes los realicé como guía turística y organizadora de los proyectos de desarrollo en las comunidades indígenas, apoyados por la Fundación Inka de la República Checa que creé en 2002 (http://www.inkaperu. $\mathrm{cz} /)$. Los proyectos, apoyados por la Fundación Inka, se llevaron a cabo en más de 60 comunidades andinas en el departamento de Cusco. ${ }^{5}$

\section{Condiciones básicas del desarrollo del turismo vivencial: estabilización política y evolución (¿revolución?) en las infraestructuras y medios de transporte}

En los últimos años se estabilizó la situación política y la seguridad ciudadana en Perú. En 1992 fue capturado Abimael Guzmán, líder del movimiento Sendero Luninoso que realizó las acciones terroristas sobre todo en la sierra peruana desde 1980. Como consecuencia de la captura del jefe del movimiento y también de otros miembros de la organización terrorista, durante los años siguientes, se dispersó y desmembró el grupo armado. Acabaron no sólo las actividades de los grupos paramilitares que amenazaron a las comunidades campesinas andinas sino también las actividades de persecución por parte del Ejército que eliminaba a las tropas armadas y sus potenciales simpatizantes o abastecedores voluntarios o forzados en el campo. Terminó la Época de violencia. ${ }^{6}$

\section{Op. cit.}

5. Véase la presentación (diaporama) de las actividades de la asociación en: www. inkaperu.cz/.../PROYECTOS\%20EN\%20PERU, página consultada el 2 de junio de 2015 (nota de los editores).

6. Acerca de Sendero Luminoso, véase Hugo Neira, Hacia la Tercera Mitad. Perú XVIXX, Lima: Editorial Herética, 2005. 657-685. Sobre Sendero Luminoso y Movimiento Revolucionario de Túpac Amaru (MRTA), véase también Rafael Vivance Arana, José 
Los turistas potenciales que hubiesen viajado por el campo andino en los años 80-90 del siglo pasado -aunque fuera por las carreteras principales-, corrían peligro de vida. Por razones de seguridad no era posible quedarse en una comunidad para conocer la vida del campo; ni turistas ni agencias de viajes hubieran tenido interés en actividades tan riesgosas. El turismo vivencial hasta el fin de los años 90 del siglo XX, fuera de los destinos turísticos más famosos, prácticamente no existía.?

Otro hecho importante para el desarrollo del turismo es que durante los últimos años disminuyeron las protestas (aunque todavía existen pequeñas muestras de ellas) de los campesinos y mineros (y otros profesionales) contra el gobierno y las empresas mineras, con frecuencia acompañados por los bloqueos de las carreteras. ${ }^{8}$ Para el movimiento turístico, la situación de paz y seguridad que se puede constatar en Perú, también en las regiones serranas, es fundamental.

Por lo demás, mejoró de manera significativa la infraestructura turística. ${ }^{9}$ Existen ofertas de alojamiento de todo tipo, desde hostales baratos para los jóvenes hasta hoteles de alta calidad. Hay posibilidades de alojamiento no solamente en las ciudades grandes sino también en las capitales de los distritos y algunas comunidades. Desde los años 90 del siglo pasado, se construyen carreteras que llegan últimamente hasta las comunidades lejanas (no en distancia sino en accesibilidad). Todavía, hace dos o tres años, para trasladarse del centro distrital a la comunidad lejana el medio de transporte común era el caballo o la mula. ${ }^{10}$ Hoy día, la gente utiliza como medio de transporte privado las

Yllanes Choque, Historia. Compendio Académico, tomo 2. Cuzco: Academia Raimondi, 2006. 243-251.

7. Informaciones de los gerentes de las agencias turísticas de Cusco y de los campesinos de los departamentos Cusco, Ayacucho y Arequipa. Entrevistas personales realizadas entre 1994 y 2002 con el fin de conocer las vías y destinos seguros para los viajes turísticos. 8. Experiencias personales. Sobre los últimos bloqueos se escribe en El Comercio: http:// elcomercio.pe/noticias/bloqueo-carreteras-521701, artículo titulado "Cuando el bloqueo de carreteras se vuelve arma política», del día 26.4.2015, consultado el 2.5.2015. Información sobre el ataque del día 7.5.2015 de los opositores del proyecto minero, véase: http://peru21.pe/actualidad/tia-maria-opositores-al-proyecto-quemaron-omnibus-interprovincial-matarani-2218319, artículo del 7.5.2015; consultado el 8.5.2015.

9. Se prevé el incremento del turismo en un $6 \%$ en los próximos diez años, debido a la inversión en infraestructura, de origen público y privado, según el presidente del Consejo Mundial de Viajes y Turismo (WTTC, por su sigla en inglés), David Scowsill. Véase: http://elcomercio.pe/vamos/noticias/turismo-peru-creceria-mas-6-proximos-10-anos-noticia-1755798, artículo del día 10.9.2014, consultado 2.5.2015.

10. Para llevar la carga se utilizaban las llamas. Los machos pueden cargar hasta $40 \mathrm{kgs}$. Las llamas fueron durante muchos siglos el mejor medio de transporte, el más práctico 
motocicletas y, gracias a la construción de las carreteras, aumentan las líneas de minibuses, posibilidades de viajes en coches colectivos o coches privados (taxis) alquilados en los centros distritales. Hay que tener en cuenta que, hace dos o tres años, por ejemplo para la visita de alguna comunidad, se necesitaban dos días de ida (a pie o a caballo) y hoy día el mismo traslado dura, en motocicleta o en coche, entre 4 y 5 horas. En las zonas donde existía una carretera, mejor dicho una pista, cuya red era muy limitada y calidad precaria, se viajaba en camiones. Las facilidades del transporte contribuyen no solamente al movimiento local (transporte al lugar de trabajo, venta de productos, visitas familiares) sino también al crecimiento turístico, incluso al turismo vivencial en las comunidades más lejanas. ${ }^{11}$

El turismo vivencial se puede desarrollar en el campo muy rápidamente gracias a algunas costumbres tradicionales como es el trabajo colectivo para el bienestar de la comunidad. La participación de los pobladores, en muchos pueblos andinos, en las actividades comunales, es fuerte. ${ }^{12}$ En las construcciones de casas que servirán para los pobladores o para el bienestar o utilidad de sus hijos, participan con entusiasmo no sólo los hombres sino también las mujeres $\mathrm{y}$ adolescentes aunque el trabajo sea voluntario, es decir no pagado. ${ }^{13}$ La cons-

en el relieve andino por poder andar por los caminos abruptos y vertiginosos, atravesar los puentes colgantes y sin necesidad de alimentarse con el pasto adecuado durante más de un mes. Los últimos años - gracias a la construcción de carreteras o pistas- las llamas (o mulas utilizadas en las regiones menos ásperas) están remplazadas por motocicletas y coches. Datos basados en las experiencias personales de las estancias en las comunidades andinas en el año 2001 con los agricultores y pastores de ovejas y llamas. Acerca de la función de las llamas, véase Steven $\mathrm{S}$. Webster, «El pastoreo en $\mathrm{Q}^{\prime}$ ero». Q'ero, el último ayllu inka. Jorge Flores Ochoa, Juan Víctor Nuñez del Prado (eds.). Cuzco: Centro de Estudios Andinos, 1983. 53-80. Informaciones sobre el reemplazo de las llamas y mulas por medios mecánicos están basadas en las experiencias personales de los viajes profesionales y la coordinación de los proyectos de la Fundación Inka y asociaciones peruanas Inka Sumaq Sonqo e Inka Sumaq Yachachiq, entre los años 2011 y 2014 en los distritos Yanaoca, Livitaca, Tungasuca, Paucartambo, Ocongate y demás.

11. Experiencias vividas durante las expediciones de los estudiantes universitarios checos y eslovacos entre los años 2010 y 2012 e informaciones de los comuneros locales durante la elaboración de los proyectos de desarrollo apoyados por la Fundación Inka. 12. Experiencias de la realización de los proyectos de desarrollo apoyados por la Fundación Inka, por ejemplo en la construcción de las bibliotecas, centros educativos, talleres de costura y tejido en las comunidades: Pucamarca, Yanaoca, Santo Domingo, Pataqueña, entre los años 2002 y 2014.

13. La costumbre de participación corresponde a la costumbre andina de apoyo mutuo en familia y comunidad, en quechua, ayni. Los pobladores se ayudan entre ellos durante las construcciones de las casas para los hijos recién casados, trabajos en la chacra, 
trucción del edificio «sencillo» se ejecuta muy rápidamente - una casa pequeña se construye en dos meses, en la época seca del año. Si la junta directiva toma una decisión que sea apoyada por la comunidad y ésta logra organizarse, la preparación de las condiciones materiales para el inicio del turismo vivencial puede ser bastante rápida.

La construcción de las habitaciones para el alojamiento potencial de los turistas es una cosa y la preparación de los campesinos para las visitas de los turistas de otros países y los nacionales de las ciudades ${ }^{14}$ es otra tarea, no menos difícil. Para tener éxito se requieren grandes transformaciones, hay que modificar las costumbres locales de preparación de la comida, que exigirá un nivel más alto de higiene, igualmente las condiciones en los baños y en los mismos dormitorios -algunos turistas, aunque quieran conocer la vida en el campo, tienen miedo de los insectos y de las enfermedades posibles. Los coordinadores de las agencias de viajes visitan las casas y escogen las habitaciones convenientes para su oferta en los paquetes turísticos. ${ }^{15}$ Tomar la decisión de participar en el turismo vivencial, también significa, por parte de los comuneros, que estén listos para dedicar su tiempo (energía y paciencia) a los clientes que desean labrar la

trabajos comunales como reparación de caminos o puentes, construcción de la casa comunal, locales para talleres, etc. Sobre el trabajo colectivo y la red de reciprocidad en las comunidades andinas, véase Catherina J. Allen, La coca sabe. Coca e identidad cultural en una comunidad andina. Cusco: Centro Bartolomé de las Casas, 2008, p. 79 y 89; también María Rostworovski de Diez Canseco, Historia del Tahuantinsuyo. Lima: Instituto de Estudios Peruanos, 2013, p. 69.

14. Según la subdirectora de turismo interno de PromPerú, Marisol Acosta Torreli, la meta para el año 2014 fue rebasar los 37 millones de viajes hacia el interior del país, superando en un millón la cifra de 2013. El crecimiento del flujo del turismo nacional en Perú se debe también a las campañas de promoción, por ejemplo por la página web ¿Y tú qué planes? Véase: http://elcomercio.pe/vamos/noticias/promperu-planea-superar-37-millones-viajes-al-interior-noticia-1720485?ref=flujo_tags_514679\&ft=nota_24\&e=titulo, artículo del 4.4.2014, consultado el 15.5.2015. Estadísticas sobre el turismo en Perú disponibles en: http://www.peru.travel/impp/, consulta del 16.5.2015. 15. Según datos, entre otros, de los coordinadores del programa vivencial en Raqchi y en Umasbamba, Chinchero; y de José Moreano, dueño de la agencia de viajes Yosematour Cusco; julio y agosto de 2014. Las condiciones básicas exigidas por los turistas participantes en el turismo vivencial se describen también en el material de la Fundación CODESPA de España: "Programa RUTAS: Metodología para el fortalecimiento de iniciativas de Turismo Rural Comunitario". Véase http://www.codespa.org/blog/publicaciones-notas-tecnicas/metodologia-para-el-fortalecimiento-de-iniciativas-de-turismo-rural-comunitario/?gclid=COqNp9zqyMUCFUfkwgodxKYA8A, página consultada el 16.5.2015. 
tierra o participar en las faenas diarias, lo que significará, para los campesinos, una cierta pérdida del tiempo.

El desarrollo del movimiento turístico en el campo depende considerablemente de los contactos que tienen los comuneros con las agencias de viajes en las ciudades. ${ }^{16}$ Aunque los jóvenes del campo estudien en las universidades las carreras de Administración de empresa, Turismo, Comunicación o Lenguas, las capacidades de promover el turismo comunal, por ejemplo vía Internet, son por el momento limitadas. Por otro lado, la comunicación entre la agencia de viajes y el coordinador del turismo en la comunidad ahora es fácil, gracias a la posesión masiva de teléfonos celulares en el campo, y la ampliación de la cobertura local. ${ }^{17}$

Otro fenómeno que facilita la existencia de los servicios del turismo en el campo es la ausencia de obstáculos administrativos: los campesinos no necesitan solicitar permisos municipales, permisos de sanidad para poder montar un restaurante, licencias profesionales o comerciales, certificados de buena salud, etc. Las condiciones administrativas para practicar los servicios turísticos son favorables. ${ }^{18}$

Es muy popular en nuestros días, y ligado estrechamente al turismo vivencial, el turismo místico. ${ }^{19}$ Sacerdotes andinos comparten su sabiduría e informaciones sobre las tradiciones espirituales $y$, a veces, dan clases de

16. Informaciones de los pobladores de Hatun Qero-Sillustani y Umasbamba que participan en los programas del turismo vivencial, 2011-2014.

17. Asesoramiento necesario de los tour operadores a los comuneros como mercado objetivo por su capacidad de enviar cada año a un número mayor de visitantes, sus condiciones de pago por adelantado y por la generación de una relación comercial a largo plazo, lo que contribuye a garantizar una cierta estabilidad, se menciona en el material de la Fundación española CODESPA, Programa RUTAS: Metodología para el fortalecimiento de iniciativas de Turismo Rural Comunitario, en: http://www.codespa. $\mathrm{org} / \mathrm{blog} /$ publicaciones-notas-tecnicas/metodologia-para-el-fortalecimiento-de-iniciativas-de-turismo-rural-comunitario/?gclid=COqNp9zqyMUCFUfkwgodxKYA8A, página consultada el 10.5.2015.

18. Informaciones facilitadas a las coordinadoras de los proyectos de desarrollo de la asociación peruana Inka Sumaq Yachachiq, en julio de 2014, por la junta directiva de la comunidad Umasbamba, distrito Chinchero, donde se ha desarrollado el programa del turismo vivencial durante los últimos tres años. La administración ligada con el levantamiento de la empresa mejoró significativamente -para concluir el registro de la Fundación Inka en Perú, que apoyó los proyectos en los Andes peruanos desde 2002, fueron necesarios más de cuatro años, mientras que, en 2014, el registro de la asociación Inka Sumaq Yachachiq (ONG) duró cinco meses.

19. Definición del turismo místico: tipo de turismo convencional referido al turismo de naturaleza religiosa, de peregrinación, en donde se realizan manifestaciones de fe 
desarrollo espiritual a los interesados que son generalmente extranjeros. La comercialización de los rituales, en algunos lugares del Perú, es criticada por unos sacerdotes andinos y algunos comuneros, y estimada por otros. ${ }^{20}$ Hay que darse cuenta de que, en muchos casos, los participantes de las ceremonias presentan sinceramente el respeto a la Madre tierra y el ambiente, durante los actos, es sagrado. Algunos sacerdotes andinos no sólo comparten la sabiduría espiritual con los extranjeros sino que también valoran y les agrada el interés por su cultura y tradiciones. Facilitan la transmisión de las informaciones sobre las tradiciones andinas sintiéndose orgullosos de su famosa cultura autóctona. El interés presentado por bastantes extranjeros por la civilización en los Andes ayuda a la revitalización de la identidad andina. ${ }^{21}$ Los extranjeros admiran los trajes típicos, los trabajos manuales de artesanía, las danzas, la música andina y la lengua quechua. Se dan cuenta de ello los jóvenes autóctonos, influidos por el respeto de los extranjeros hacia las tradiciones andinas, vuelven a valorar sus tradiciones, $\mathrm{o}$ se fortalece su actitud hacia las representaciones de la identidad de su pueblo. ${ }^{22}$

como procesiones, etc. Fuente: Aliaga, Cabrera Nieri, Carbajal Barreda, Capacitación en estándares de calidad y buenas prácticas de turismo sostenible, op. cit.

20. Opiniones de los sacerdotes y comuneros Q'eros y curanderos de Huasao (Cuzco), confirmadas en las múltiples reuniones celebradas con ellos entre 2002 y 2008.

21. Entrevistas con población local durante y después de las ceremonias, en las cuales participé entre 2005 y 2014, en las comunidades: Pucamarca, Cuper, Chinchero, Kirkas, Punacancha, Yanaoca, Tinta, Mosoqllaqta, Thumi, y demás. Las ceremonias son realizadas cada año para lograr, entre otras cosas, el éxito de la realización de los proyectos de desarrollo, para la salud de los estudiantes apoyados por la Fundación Inka, etc.

22. Afirmaciones basadas en experiencias personales de más de 10 años de realización de proyectos de desarrollo en las comunidades andinas en el marco de la Fundación Inka, cuyas actividades están vinculadas con la revitalización de la identidad. A pesar del tiempo transcurrido y de la rápida extensión de programas y proyectos de turismo responsable en América Latina, en general, y en el Perú en particular, son muy escasos los estudios formulados desde una perspectiva sociocultural que incida en los actores y que permitan entender en toda su amplitud las circunstancias en las cuales la población local define su participación en estas iniciativas turísticas y el tipo de agencia que desempeñan en relación a su género, generación, etnia y clase social. Véase al respecto, el artículo de Beatriz Galán: Nuevas y viejas narrativas turísticas sobre cultura indígena en proyectos de turismo responsable en los Andes, http://www.google.cz/url?sa=t\&rc$\mathrm{t}=\mathrm{j} \& \mathrm{q}=\& \mathrm{esrc}=\mathrm{s} \&$ source $=$ web\& $\mathrm{cd}=2 \& \mathrm{ved}=0 \mathrm{CCcQFjAB} \& u r l=h t t p \% 3 \mathrm{~A} \% 2 \mathrm{~F} \% 2 \mathrm{Fe}-\mathrm{spa}-$ cio.uned.es\%2Ffez\%2Feserv\%2Fbibliuned\%3A500383-Libros-5470\%2FDocumento. pdf\&ei=Z_aSVdDEHcG2UdaqscAM\&usg=AFQjCNGP_-3Cmj5op6wkGEWFf4JtnQGZkA\&bvm=bv.96783405,d.d24, documento pdf. consultado el 26.6.2015. 


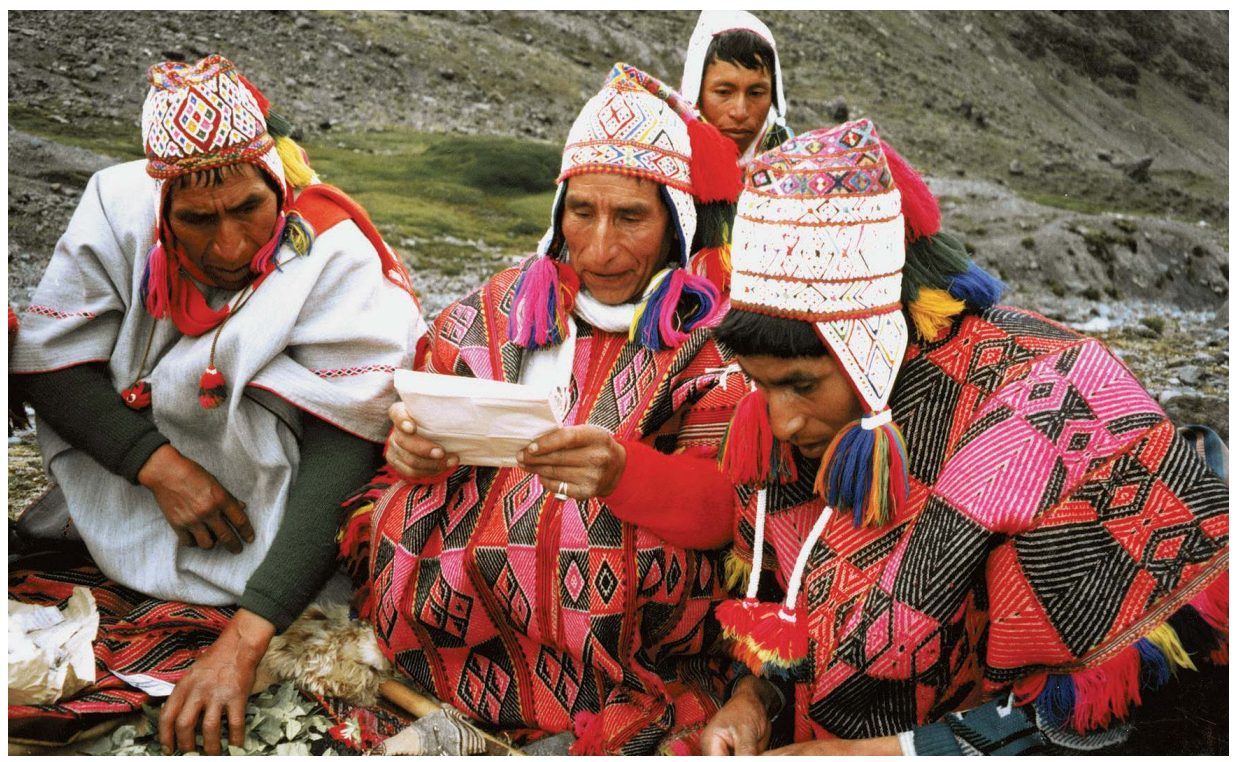

Foto 1 - La ceremonia «Pago a la Madre tierra», 2002.

El gobierno peruano promueve el turismo en el país. La Dirección Nacional de Desarrollo Turístico, del Ministerio de Comercio Exterior y de Turismo (MINCETUR), coordina el desarrollo y ejecución de los proyectos de interés turístico que realicen los organismos regionales, los gobiernos locales $\mathrm{u}$ otros organismos públicos. Proyectos que sean rentables socialmente, sostenibles y enmarcados en las políticas del sector, desarrollando un turismo sostenible, orientado a generar desarrollo económico y social al país. Existe el programa nacional de turismo rural comunitario que está basado en la participación local como elemento fundamental que permita la sostenibilidad de la actividad turística (como actividad económica complementaria), y la inclusión social y económica de las poblaciones rurales a través del desarrollo de productos y servicios diversos. El objetivo de los programas es contribuir, desde las zonas rurales, al desarrollo de un turismo sostenible como herramienta de desarrollo económico-social del Perú. El programa en Perú, actualmente, apoya 72 proyectos (también en los departamentos de Cusco y Puno) y se genera un aporte de $12 \%$ como incremento de la empleabilidad en turismo en zonas rurales, predominantemente por la incorporación de la mujer. Según la estadística del MINCETUR, cerca de 100 mil visitantes extranjeros hacen turismo en zonas rurales manejadas por organizaciones de base comunitaria. ${ }^{23}$ También algunas Organizaciones

23. Véase http://www.mincetur.gob.pe/newweb/Default.aspx?tabid=2333, página consultada el 25.3.2015. 
no Gubernamentales (sin fin de lucro) y algunas agencias de viajes apoyan los proyectos de desarrollo turístico en el campo -desde la investigación de la oferta (recursos turísticos, oferta de servicios, accesibilidad y servicios básicos), preparación de los recursos audiovisuales (fotos, vídeos), orientación a los pobladores locales (por charlas y consejos prácticos), hasta la oferta de los paquetes turísticos. Se pueden mencionar, como ejemplos de organizaciones peruanas: Pro Desarrollo Turístico (PRODESTUR), ${ }^{24}$ la Asociación Inka Sumaq Yachachiq, ${ }^{25}$ la Asociación de Promoción y Desarrollo Agrario, el Progreso Agrario“26 y la agencia turística RESPONS (Responsible Travel Peru). ${ }^{27}$

\section{Ejemplos y casos de desarrollo del turismo en algunas comunidades andinas}

En esta segunda etapa de la exposición, se evocarán diferentes casos de iniciativas y adaptaciones a la demanda turística, con sus consecuencias, benéficas en la mayor parte de los casos, para las poblaciones.

Algunas comunidades están presentes en el turismo desde hace más de treinta años, por ejemplo en las islas Uros y en la isla Taquile del lago Titicaca. ${ }^{28}$

\section{Iniciativas y adaptaciones en islas del lago Titicaca}

Esta primera oferta turística en las islas Uros y en la isla Taquile incluía -a parte de alojamiento y comida- la presentación de danzas folclóricas, venta de artesanía local muy bien trabajada y, últimamente, también la participación en la ceremonia andina de Pago a Pachamama - Madre tierra, ${ }^{29}$ y el transporte en

24. Véase https://prodestur.wordpress.com/about/proyectos/, página consultada el 25.6.2015.

25. Informaciones de los coordinadores de la asociación Inka Sumaq Yachachic cuyos proyectos son apoyados por la Fundación Inka checa.

26. Véase http://www.ongproa.com/turismo_solidario.html, página consultada el 25.6.2015.

27. Véase http://www.responsibletravelperu.com, consulta del 25.6.2015.

28. El proyecto en las islas Uros y en Taquile pertenece a los primeros proyectos del turismo vivencial en Perú. Véase http://munaytaquile.jimdo.com/historia, página consultada el 25.6.2015. Informaciones basadas también en la experiencia personal de los viajes turísticos con los grupos checos y estudiantes peruanos (aproximadamente 30 viajes) entre los años 1995 y 2013 y encuestas realizadas con los pobladores taquileños. Sobre la cultura Uros, véase: https://www.youtube.com/watch?v=z89FPPsYkWM, última consulta el 17.5.2015.

29. La ceremonia del Pago a Pachamama (Madre tierra) es el ritual más frecuente entre los pobladores andinos. Con la realización de la ceremonia se presenta el respeto a la Madre tierra y a los Apus -dioses de las montaňas. Se les dedican las 
lanchas desde la ciudad de Puno. ${ }^{30}$ El flujo de los turistas trajo los beneficios económicos a los pobladores, los cuales cuidaron la distribución justa de los turistas para que el beneficio tocara la mayoría de la población. Inspirados por los éxitos (económicos) de sus vecinos de la isla Taquile, los pobladores de la isla Amantani comenzaron a ofrecer también un paquete turístico, cada vez más adaptado a los gustos de los turistas: unificaron su vestimenta típica, sobre todo las mujeres. En ambas islas mejoraron fuertemente las condiciones higiénicas del alojamiento en general, incluso los baños. ${ }^{31}$

Se puede decir que el movimiento turístico influye considerablemente en la economía local. Los ingresos del turismo facilitan un nivel de vida más alto que los beneficios de los pescadores y agricultores dado las condiciones precarias altoandinas, aún más limitadas en las islas. Se nota el mejoramiento no sólo de las viviendas en general, sino también en el arreglo de los caminos, en las plazas, más cuidadas, en las islas, en las escuelas, etc. En este caso de desarrollo bajo la influencia del movimiento turístico, se puede constatar la satisfacción tanto de turistas como de comuneros, incluso

ofrendas tanto naturales como algunas preparadas especialmente para el ritual, que se compran en los mercados. Se utilizan las hojas de coca, productos agrícolas granos de maíz, fríjoles, lentejas, arroz, también caramelos, cebo de llama, claveles. Se adjuntan los objetos, miniaturas fabricadas a partir de chapa o de otro material, que representan los deseos de la gente, por ejemplo poseer un rebaño grande (deseo representado por la figura de una llamita), tener novio, casarse (figura del joven o corazón), hijos (figura del bebé), trabajo (figuras de los instrumentos laborales), etc. Las ofrendas se ofrecen a los dioses de las montañas cercanas situadas en los cuatro puntos cardinales, a las más altas de la región y a las de la zona de los participantes de la ceremonia. Se colocan las ofrendas sobre una hoja de papel, en la mesa ceremonial, mientras el sacerdote andino que dirige la ceremonia reza e invoca a los dioses; a continuación se envuelven y empaquetan dichas ofrendas para quemarlas en una pequeña hoguera sagrada cercana al lugar de la ceremonia. Dependiendo de la rapidez en que se queman, o la forma de las llamas, se puede saber si la ofrenda ha sido aceptada, o no, por los dioses. Las deidades Madre tierra, los Apus y el ritual del Pago a Pachamama son descritos en el estudio de Washington Rozas, «Los Paqo en Q'ero». Jorge Flores Ochoa, Juan Víctor Nuñez del Prado (eds.). Q'ero, el último ayllu inka, op cit., págs. 143-158. Y en Jorge Flores Ochoa, Ana María Fries, Puna, qheswa, yunga. El hombre y su medio en Q'ero. Lima: Banco Central de Reserva del Perú, 1989.

30. Informaciones basadas en la experiencia personal de los viajes turísticos entre los años 1994 y 2013 y encuestas realizadas con los pobladores taquileños.

31. Experiencias personales de varias visitas turísticas como tour operador de las agencias checas y expediciones de los estudiantes universitarios checos, en la isla Amantani entre los años 1997 y 2012. 
el mejoramiento controlado del medio ambiente y el fortalecimiento de la identidad étnica. ${ }^{32}$

\section{Islas Uros: un ejemplo con consecuencias dañinas}

Otro efecto de crecimiento del turismo en la zona fue la multiplicación de la construcción de islas flotantes Uros, islas prefabricadas en la Bahía de Puno, a poca profundidad, que sirven como destino turístico para los tours de dos o tres horas en barcos que salen de la ciudad de Puno. En las islas Uros se ofrece -a parte de una explicación acerca de la vida en las islas en una charla presentada por un poblador local- la venta de mercancía (fabricada sobre todo en Puno y en otras zonas del Perú), también comida y alojamiento (raramente aprovechado por los turistas). ${ }^{33}$

La construcción masiva de las nuevas islas (por los jóvenes de la zona o los de Puno y alrededores) en la cual se utilizan, a parte de totora, ${ }^{34}$ también botellas plásticas (como material de base enrollado con totora), presenta un fuerte riesgo de contaminación del lago Titicaca. Las islas antiguas construidas de pura totora, material natural, a lo largo de los años se iban deteriorando, lo que provocaba que las personas que las habitaban o bien se trasladaban a tierra firme o bien construían nuevas islas donde habitar. Estas islas deterioradas se descomponían y dispersaban, así desaparecían en el lago, sin dejar residuos. Lamentablemente no se puede constatar el mismo fenómeno de desaparición total después del abandono de las islas modernas semiplásticas. El mismo riesgo lo presentan los barcos tradicionalmente construidos igualmente de totora en cuya fabricación se utilizan actualmente las botellas plásticas; estos barcos se construyen para el uso turístico. ${ }^{35}$ En Puno, se llevan a cabo discusiones sobre la amenaza de este nuevo tipo de contaminación del lago y se discuten las medidas para frenar o controlar las actividades de los

32. Confirmaciones de los profesores de las escuelas y de los coordinadores de los proyectos de desarrollo en el marco del turismo vivencial. Véase también Aliaga, Cabrera Nieri, Carbajal Barreda, Capacitación en estándares de calidad y buenas prácticas de turismo sostenible, op. cit.

33. Sobre el viaje a las islas, véase: http://www.islahananpacha.com/?c=pagina\&m=ver\&p=historia\&idioma $=\mathrm{es}$, última consulta el 26.6.2015.

34. Según el DRAE (22. ${ }^{\text {a }}$ edición), palabra derivada del quechua tutura, que designa una "planta perenne, común en esteros y pantanos, cuyo tallo erguido mide entre uno y tres metros, según las especies. Tiene uso en la construcción de techos y paredes para cobertizos y ranchos.»

35. Los mismos pobladores utilizan como medio de transporte las lanchas públicas o sus barcos privados hechos de madera, con fuerza motriz, no los fabricados con totora. 
pobladores de las islas. ${ }^{36}$ En este caso, el desarrollo turístico masivo implica, secundariamente, efectos negativos sobre el medio ambiente. ${ }^{37}$

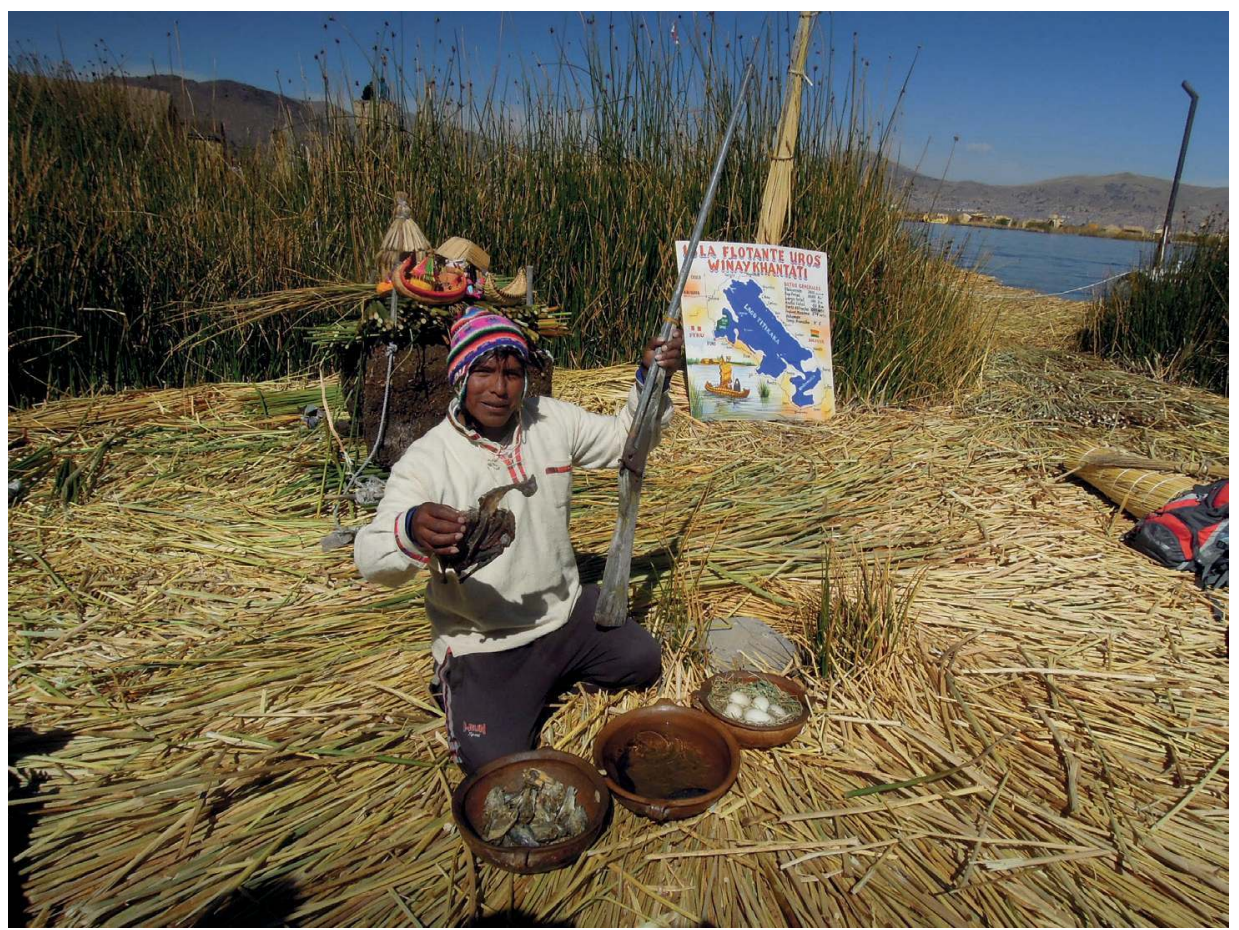

Foto 2 - Presentación de la vida cotidiana en las islas Uros, 2014.

36. Entrevistas con los propios pobladores de las islas y habitantes de la ciudad de Puno, agosto de 2014.

37. En el lago Titicaca se nota el crecimiento de la contaminación. El desordenado crecimiento demográfico de la ciudad de Puno en Perú, Copacabana en Bolivia y los desagües clandestinos también de otras ciudades cercanas al lago, dejan grandes niveles de contaminación. El presidente de Perú, Ollanta Humala, anunció grandes inversiones para la construcción de las plantas de tratamiento que permitan limpiar el lago, con la finalidad de frenar la contaminación. Véase http://www.eldiario.net/ noticias/2015/2015_05/nt150527/nacional.php? n=26\&-bolivia-y-peru-realizan-estudio-ambiental-en-lago-titicaca, artículo del 27.5.2015, consultado el 26.6.2015. Los presidentes de Perú y Bolivia se encontraron el 23.6.2015 en Puno para resolver problemas de la contaminación del lago Titicaca y otros, véase http://gestion.pe/politica/ollanta-humala-gabinete-binacional-peru-bolivia-paso-historico-2135470, artículo del 23.6.2015, consultado el 26.6.2015. Véase también: http://peru21.pe/mundo/ titicaca-contaminacion-amenaza-uno-grandes-lagos-planeta-2221673, artículo del 25.6.2015, consultado el 26.6.2015. 


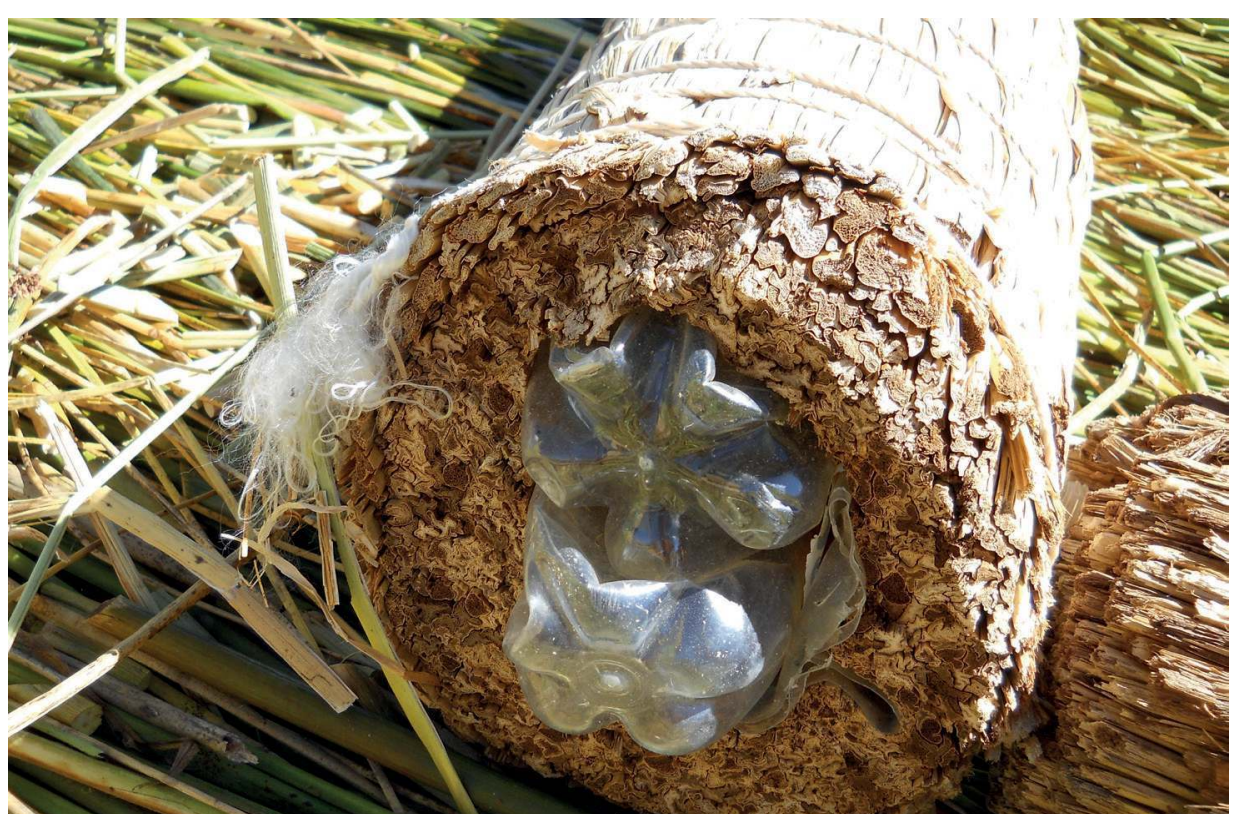

Foto 3 - Un banco elaborado con totora y botellas plásticas, Uros, 2014.

\section{Sillustani, una comunidad en tierra firme: otro caso de oferta turística}

Cerca del lago Titicaca, entre la carretera que conecta Puno con Juliaca, y Sillustani (destino turístico por las famosas chullpas, las torres funerarias preincas e incas), situadas en la península de la laguna Umayo, se encuentran las casas indígenas típicas de la comunidad Hatun Qolla. ${ }^{38}$

38. La palabra hatun en quechua significa grande. Véase Antonio Cusihuaman, Diccionario quechua. Cusco- Collao. Cuzco: Centro Bartolomé de las Casas, 2001. Cuzco-Collao es una rama dialectal del quechua hablado en el sur del Perú, Bolivia y norte de Argentina (nota de los editores). La ortografía de la lengua quechua no está unificada, generalmente la $h$ no se pronuncia y con frecuencia no se escribe. Véase Olga Vilímková, Základy jazyka quechua, učebnice pro samouky. /Quechua básico, manual para autodidactas/. Praga: Universidad de Economía-Oeconomica, 2005. La cultura qolla o mejor dicho el pueblo qolla fue muy importante en el pasado andino. Una de las cuatro partes que formaron el famoso imperio inca Tawanstinsuyu (tawa en quechua significa cuatro, suyu - parte) se llamó Qollasuyu. De la capital del pueblo qolla no quedó prácticamente nada. Sin embargo, el cementerio de la élite, donde más tarde sepultaron a sus difuntos también los incas, hoy día llamado Sillustani, es impresionante, por su localización en la península del lago Umayo y construcciones preciosas de las torres funerarias. Véase https://www.youtube.com/watch?v=71q7AZ7m1-Y, última consulta el 16.5.2015; también http://titicacaperu.com/cultural_sillustani.html, y https://www.youtube.com/wat$\mathrm{ch} ? \mathrm{v}=5 \mathrm{mTkp} 7 \mathrm{oWyJ} 0$, últimas consultas el 16.5.2015. 


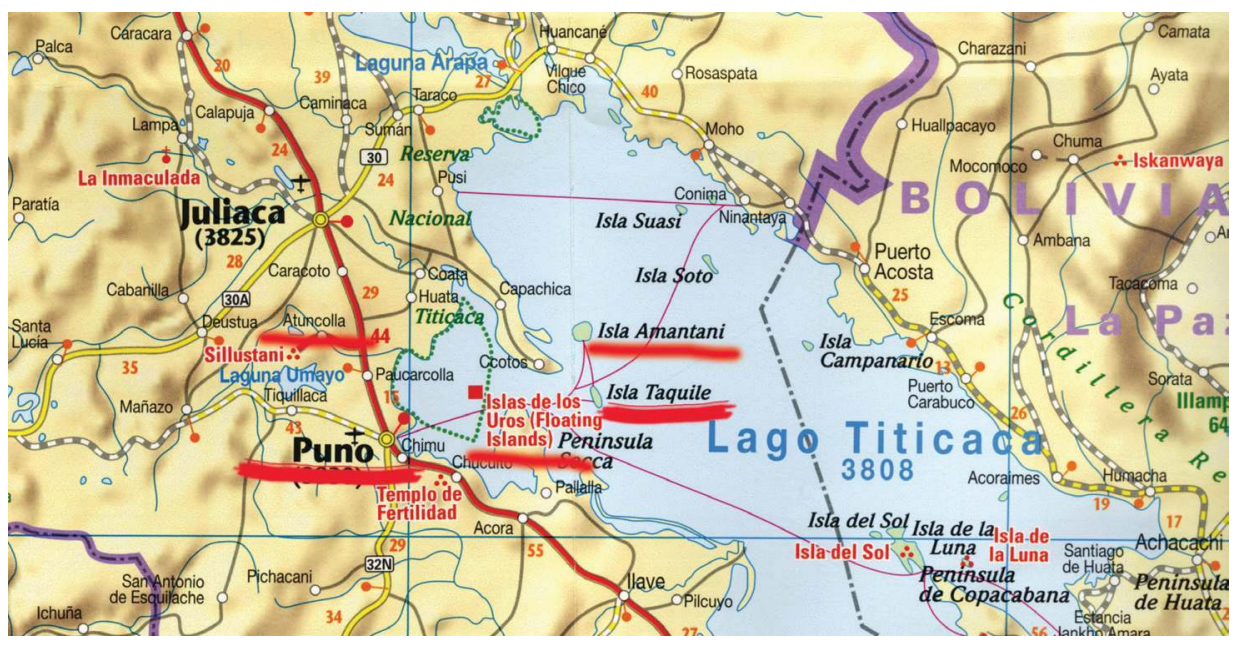

Mapa 1 - Lago Titicaca y laguna Umayo con los lugares descritos en el artículo: las islas Uros, Taquile, Amantani y comunidad Hatun Qolla (Atuncolla). Concepción: Renata Stipková, 2015.

La idea de presentar las viviendas típicas y la vida actual de los pobladores andinos nació hace algunos años ${ }^{39}$ y durante los primeros años de su existencia, las casas fueron muy bien cuidadas (mucho más que las casas habituales) y los pobladores mostraban con entusiasmo su modo de trabajo (aunque se tratase del modo de trabajo -en algunas demostraciones- de sus antepasados). Parece que los pobladores se cansaron de las visitas diarias de los turistas: actualmente, las casas no son tan pintorescas como antes y en su mayoría desaparecieron las muestras del trabajo de labrar la tierra, hilar o tejer. Las mujeres siguen presentando a los turistas los animales de crianza en la zona, sobre todo las llamas o alpacas, también las plantas cultivadas; y ofrecen las comidas típicas, por ejemplo variedades de papa con salsa de «barro», sopa de quinoa, etc. El repertorio de la oferta lo completa la venta de productos, sobre todo de tejidos locales, fabricados en Puno, o los toritos de Pucará, animalitos de cerámica fabricados en la zona o traídos de la comunidad Pucará. ${ }^{40}$ Bajó la oferta de demostraciones

39. El proyecto en Hatun Qolla pertenece a los proyectos importantes del turismo vivencial en Perú. Experiencia personal de los viajes turísticos entre 1994 y 2014.

40. Los toritos de Pucará se colocan sobre los techos de las casas para proteger el hogar contra los malos espíritus. Junto a los toritos se ponen a veces otros símbolos de protección, por ejemplo la cruz cristiana o flores. En algunos lugares hay costumbre de echar a los toritos chicha (bebida de maíz fermentada) y agua. Prácticas observadas en las comunidades de Hatun Qolla, Pucará, Pisaq. Véase también el artículo del antropólogo Fredy Reyes Apaza sobre "La simbología totémica del torito de Pucará», http:// www.cpap.pe/node/71; y http://www.terra.com.pe/especiales/mitorito/historia2.html, últimas consultas el 03.6.2015. 
de trabajo andino pero sigue en pie la posibilidad de pernoctación y alimentación (desde refrescos hasta menús) y la gente autóctona no rechaza la petición de los turistas de su posible participación en los trabajos cotidianos del campo, pastoreo de animales, llamas y ovejas, fabricación de adobe (ladrillo secado al sol), etc. Comparado con otras localidades de los Andes, el paquete turístico comprado y pagado en el lugar mismo es relativamente barato. El movimiento turístico no es la única fuente de ingresos financieros ni presenta sumas importantes para la familia. Sin embargo, es un aporte notable. El turismo (de visitas cortas y participativo) no provoca ningún impacto negativo ni en el ambiente ni en las relaciones entre los comuneros. ${ }^{41}$

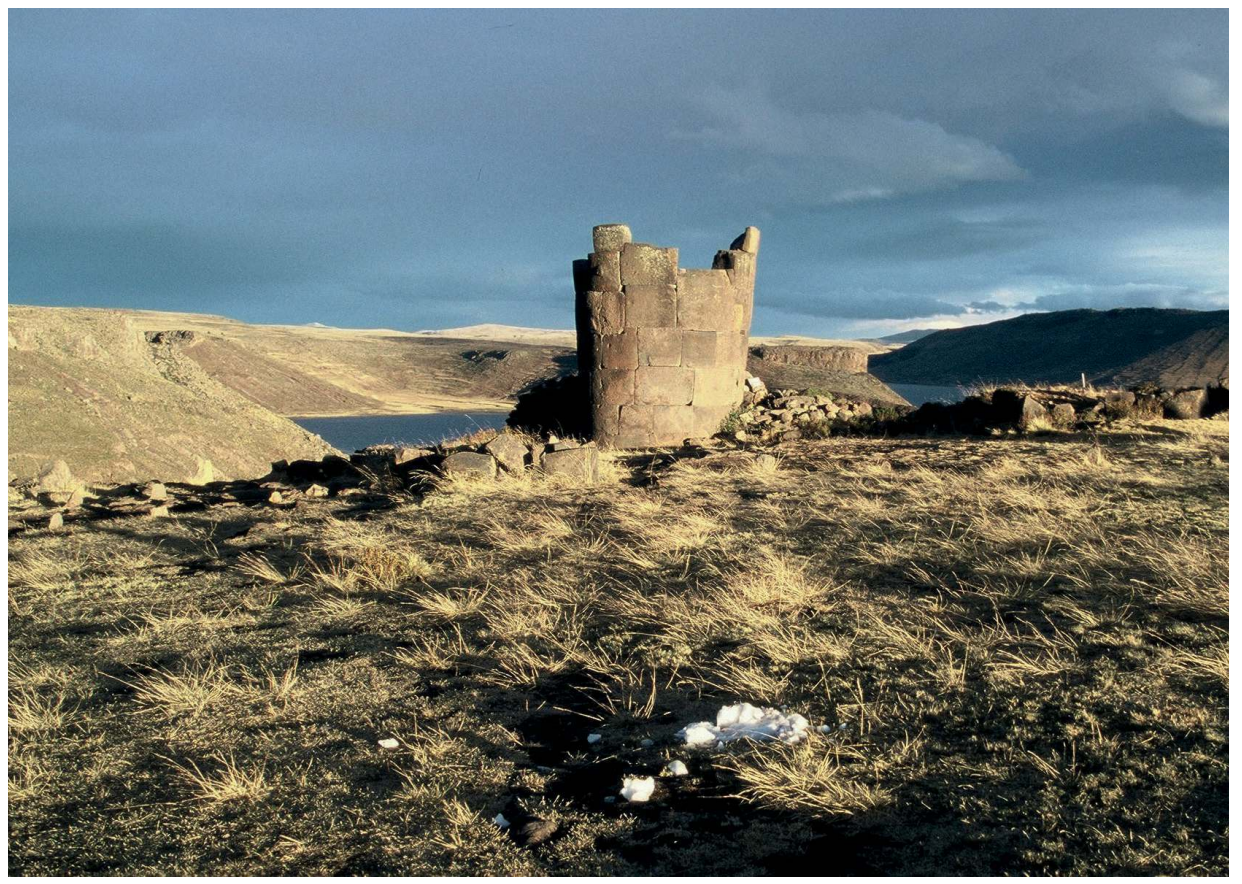

Foto 4 - Chullpa inca de Sillustani, de la necrópolis antigua situada a orillas de la laguna Umayo, 2002.

41. Entrevistas con los comuneros de zonas que promueven el turismo vivencial con éxito durante los viajes de observación e intercambio de experiencias con otros comuneros que van a comenzar a desarrollar los proyectos de desarrollo de la asociación Inka Sumaq Yachachiq, en las comunidades del distrito Yanaoca, 2009-2012. El proyecto de la asociación de turismo vivencial de los Qollas Sillustani «Asturis» de la comunidad Atuncolla está descrito en: http://titicacaperu.com/es/proyecto-educativo-sillustani.html, consulta del 9.5.2015. En la comunidad, se propuso también el Proyecto Educativo Local Atun Qolla al 2018. Véase http://ugelpuno.edu.pe/web13/node/132, documento pdf., p. 14, consultado el 17.5.2015. 


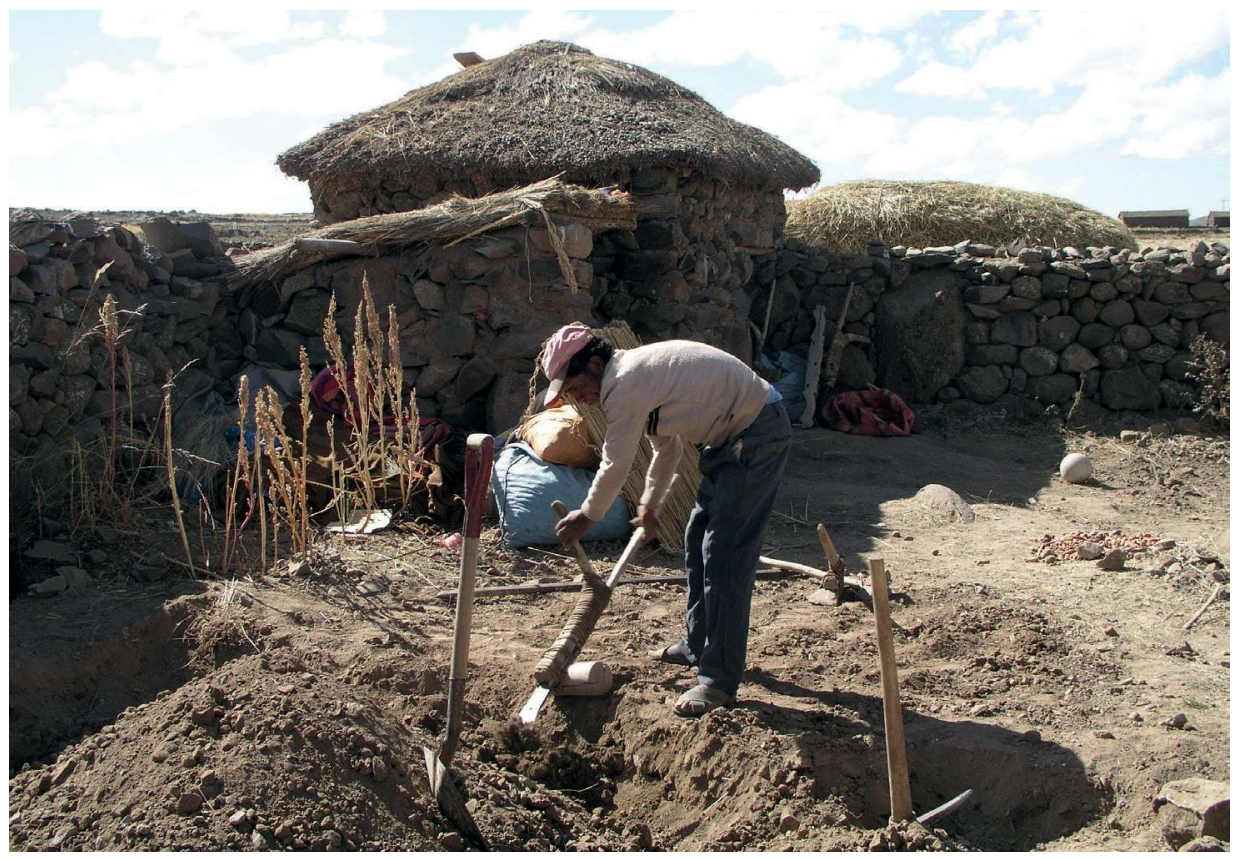

Foto 5 - Presentación del trabajo en el campo - campesino labrando la tierra en Hatun Qolla, 2007.

\section{El aprovechamiento en la comunidad de Raqchi}

Ya en el departamento de Cusco, como ejemplo de impacto fuerte del movimiento turístico -cambio considerable del ambiente (medio ambiente y relaciones entre la gente) y de la vida cotidiana de los campesinos-, se puede mencionar la comunidad de Raqchi, ${ }^{42}$ situada en la ruta turística principal entre la ciudad de Cusco y el lago Titicaca.

La posición estratégica de la comunidad (como ellos la denominan por estar situada al lado de la carretera, a tres horas de Cusco en bus) favorece la entrada fluida de turistas, sobre todo después de la construcción de una carretera asfaltada a finales de los años 90 del siglo pasado. ${ }^{43}$ Viajando desde Cusco, la pausa planeada en Raqchi por la gran mayoría de las agencias de viajes y los

42. Las informaciones sobre esta comunidad se basan en los estudios de la Junta Directiva de la Fundación Inka, que becaba entre 2002 y 2008 a los estudiantes con mejores resultados académicos.

43. La carretera entre Cusco y Puno que pasa a $1 \mathrm{~km}$ de Raqchi ha sido asfaltada en el marco del Proyecto de Desarrollo del Corredor Puno-Cusco, 1998. Al proyecto de construcción de la carretera se añade: el concepto de corredor socioeconómico; las relaciones urbano-rurales; y las actividades microempresariales, las oportunidades de negocios y el desarrollo de los mercados locales de bienes y de servicios. Véase: http:// www.ifad.org/evaluation/public_html/eksyst/doc/thematic/pl/peru_s.html. El IFAD 
buses turísticos, ${ }^{44}$ lleva a los comuneros una oportunidad interesante de ingresos. Los turistas pueden pasear por el sitio arqueológico del templo de Raqchi, de estilo arquitectónico único, ${ }^{45}$ visitar la zona de los depósitos incas recién restaurados. Todo resulta situado en una zona tranquila y agradable con un pequeño riachuelo y estanque. Se puede fácilmente observar a lo largo de los años el florecimiento que la comunidad de Raqchi ha experimentado gracias al movimiento turístico. Los buses paran cerca de la plaza del pueblo, encabezada por una pequeña iglesia. En la misma plaza hay posibilidades de refresco, baños públicos y venta de artesanías. Antes, la comunidad de Raqchi fue famosa en la zona por la producción de cerámica; actualmente (2014), en la comunidad, hay solamente dos talleres de producción de cerámica. Sin embargo,varias personas se dedican a la pintura de los productos. La mayoría de los objetos que se venden en el pequeño mercado de la plaza se importa de otras zonas (de Pisaq, Cusco, Juliaca, etc.). ${ }^{46}$

A no ser la venta de productos y servicios turísticos «rápidos» (baños, refresco) que se ofrecen a los viajeros durante la pausa en su viaje, muy importante para la comunidad es también el sector turístico participativo-turismo vivencial. Trece familias ofrecen habitaciones dobles o triples (en total, hay 30 camas disponibles en la comunidad). Los precios del alojamiento en las casas privadas son bastante elevados. La asociación Turismo Vivencial Raqchi, que determina las reglas, fijó el precio del paquete turístico en 35 dólares americanos y

(International Fund for Agricultural Development), es una agencia especializada de la ONU que realiza inversiones a favor de la gente rural. Página consultada el 9.5.2015.

44. Algunas compañías de buses que paran en Raqchi en la ruta entre Cusco y Puno, su horario y precios: http://www.inkaexpress.com.pe/,www.peruboliviaexpeditions.com, http://www.titicacatour.com/bus-turistico-cusco-puno/, compañía Perú Bus: http:// www.cuscopunobus.com/, http://www.turismomer.com.pe/servicio-turistico-cuscopuno-bus-puno-cusco-ruta-del-sol-tours-en-puno.html, http://www.turismoboliviaperu.com/pagesp/peru/bus_turistico.php, páginas consultadas el 17.5.2015.

45. Sobre Raqchi, véase el libro de René Rodriguez Arque. Raqchi, maravilloso y majestuoso parque arqueológico. Cuzco: Inetgraff, sin año de publicación. Véase también el libro de Valentín Quispe Maxi. Raqchi, Ignoto y Misterioso Complejo Arqueológico. Sicuani: Canchis,1999; así como http://peru21.pe/noticia/331457/raqchi-legado-inca; galería de fotos en: http://es.wikipedia.org/wiki/Racchi 17.5./, p. 49-51; páginas consultadas el 17.5.2015.

46. Confirmaciones proporcionadas por las mujeres vendedoras de Raqchi, julio de 2014. -Entre 2003 y 2008, la Fundación Inka becaba a los estudiantes provenientes de Raqchi en el colegio de Queromarca (comunidad cercana a Raqchi); actualmente, apoya a tres estudiantes matriculados en la Universidad San Antonio Abbad, Cusco, en las carreras de Administración de la empresa, Agronomía e Ingeniería civil. 
el precio de 25 dólares por persona (cama) y desayuno. ${ }^{47}$ Teniendo en cuenta las condiciones básicas, por ejemplo los servicios higiénicos compartidos en el patio y de relativamente bajo nivel de higiene, el precio del cuarto doble (50 dólares) es más alto que el de los hostales agradables en Cusco. Aunque los pobladores proclamen que se trata de un precio común, es habitual que los extranjeros paguen más que los turistas nacionales, cuyo número en Perú crece constantemente. ${ }^{48}$ Tanto los turistas extranjeros como los nacionales aprovechan el paquete del turismo vivencial que incluye, además de las prácticas mencionadas anteriormente de alojamineto y actividades cotidianas, la visita a un taller de cerámica y un paseo al mirador de la comunidad. ${ }^{49}$

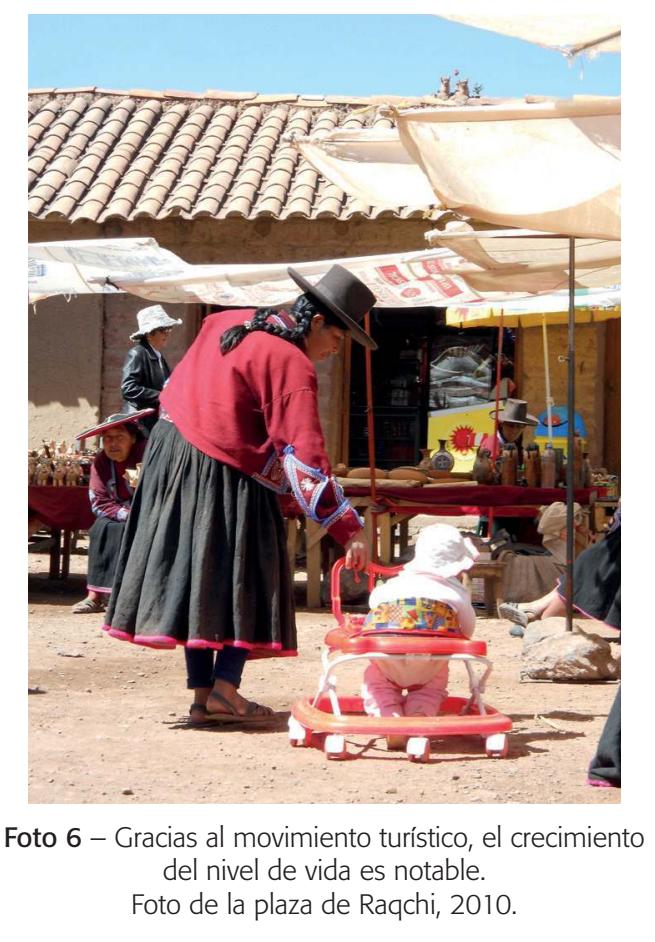

47. Precios pedidos por el presidente de la asociación Turismo Vivencial Raqchi en julio de 2014; experiencia personal de mi trabajo de tour operador con grupo de turistas checos interesados por pernoctación en Raqchi. Contacto: Asociación Raíces Incas Turísmo Vivencial Raqchi, 084984602153.

48. Esta diferenciación de precios no aparece por escrito en los folletos turísticos pero es una práctica habitual de la región.

49. El mirador se encuentra a 10 minutos de subida a pie de la plaza de Raqchi. Desde el cerro del mirador se ofrece una vista maravillosa al sitio arqueológico (al templo de Viracocha), al valle del río Vilcanota y al volcán cercano. 


\section{Raqchi inspira a otras comunidades}

Los éxitos de los comuneros en Raqchi -los ingresos financieros y el mejoramiento del ambiente de la comunidad en general (calles limpias, casas arregladas, toque pintoresco del pueblo)- se discuten en otras comunidades cercanas (por ejemplo en Mosoqllaqta o Santo Domingo ${ }^{50}$ ) cuyos habitantes conocen Raqchi, como era hace 10 años, cuando el pueblo no se distinguía de sus vecinos. El crecimiento del nivel de vida y sobre todo el mejoramiento del ambiente comunal inspiran a las juntas comunales de los alrededores. Entre las discusiones sobre un cambio posible en otras comunidades, destaca el ejemplo de Raqchi cuyos pobladores lograron organizarse, unirse y respetar las decisiones del presidente y de la junta directiva, lo que es -según las autoridades de otras comunidades- la condición básica del éxito y el objetivo a conseguir: la aceptación consensuada de los nuevos acuerdos por parte de toda la población implicada.

Las comunidades mencionadas más arriba -Mosoqllaqta y Santo Domingo (distrito Acopia) - se encuentran en la zona del circuito de Cuatro lagunas, y están situadas en las orillas de dichas lagunas, así que pueden ofrecer diversos atractivos turísticos: un paisaje muy bonito con zonas lacustres y vistas a los nevados de la Cordillera Vilcanota, un tour al Puente Inca, construcción de paja sobre el río Apurimac, aire puro, gastronomía y la participación en actividades cotidianas - pesca, pastoreo de llamas y ovejas, trabajo en la chacra (o sea en el campo). El desarrollo turístico, lo favorece la carretera asfaltada recién terminada (en 2014) que llega a las comunidades del altiplano, condición básica, según los alcaldes, del desarrollo de la zona. ${ }^{51}$ Las juntas directivas de las comunidades están discutiendo la posibilidad de hacer cursos de formación que den las agencias de viajes, a los comuneros en los pueblos, para promover el turismo vivencial. ${ }^{52}$

50. Informaciones facilitadas por las juntas directivas de las comunidades en cuestión, para la elaboración de los proyectos de desarrollo en colaboración con la asociación Inka Sumaq Yachachiq, 2012-2014, cuyos proyectos son apoyados por la Fundación Inka checa; documentos internos.

51. Según testimonios de los propios habitantes, entre 2008 y 2014.

52. Confirmaciones proporcionadas por las dueñas de las casas donde se alquilan las habitaciones para los turistas, participantes del programa del turismo vivencial en Umasbamba, Chinchero, julio de 2014. En la película documental Turismo Vivencial en las islas de Taquile y Uros, la coordinadora del turismo vivencial en las islas Uros del lago Titicaca confirma haber recibido el curso de capacitación. Véase : https://www.youtube. com/watch? $\mathrm{v}=\mathrm{yLiXvYW}$-xG0, minuto 5:03 del reportaje (precisión de los editores); consultado el 15.5.2015. 


\section{Los Q'eros: ejemplo de evolución en las zonas de asentamiento y de turismo}

De acuerdo con la evolución económica ${ }^{53}$ en Perú se nota, en los últimos años, cierto cambio en las destinaciones -circuitos turísticos y lugares populares en el campo del turismo vivencial. En algunas regiones, nuevas comunidades entran en los proyectos de dicho turismo, en otras zonas el flujo de turistas disminuye, por ejemplo por la razón de la pérdida de los «atractivos turísticos». Gracias al crecimiento de las oportunidades de trabajo también en la sierra (en la construcción de las carreteras y de los edificios en las ciudades y centros comunales, trabajo en la minería, etc.) muchos pobladores de las zonas altoandinas bajaron de sus comunidades donde se dedicaban sobre todo al pastoreo y se trasladaron a los centros en los valles. En consecuencia de los cambios locales, el turista pierde interés en visitar dicho lugar prácticamente abandonado por los pobladores. Una muestra de este cambio de preferencias en los destinos andinos es una zona muy popular para el senderismo (trekking), turismo vivencial o místico que era la región habitada por la comunidad de los Q'eros, situada entre Paucartambo y Ocongate.

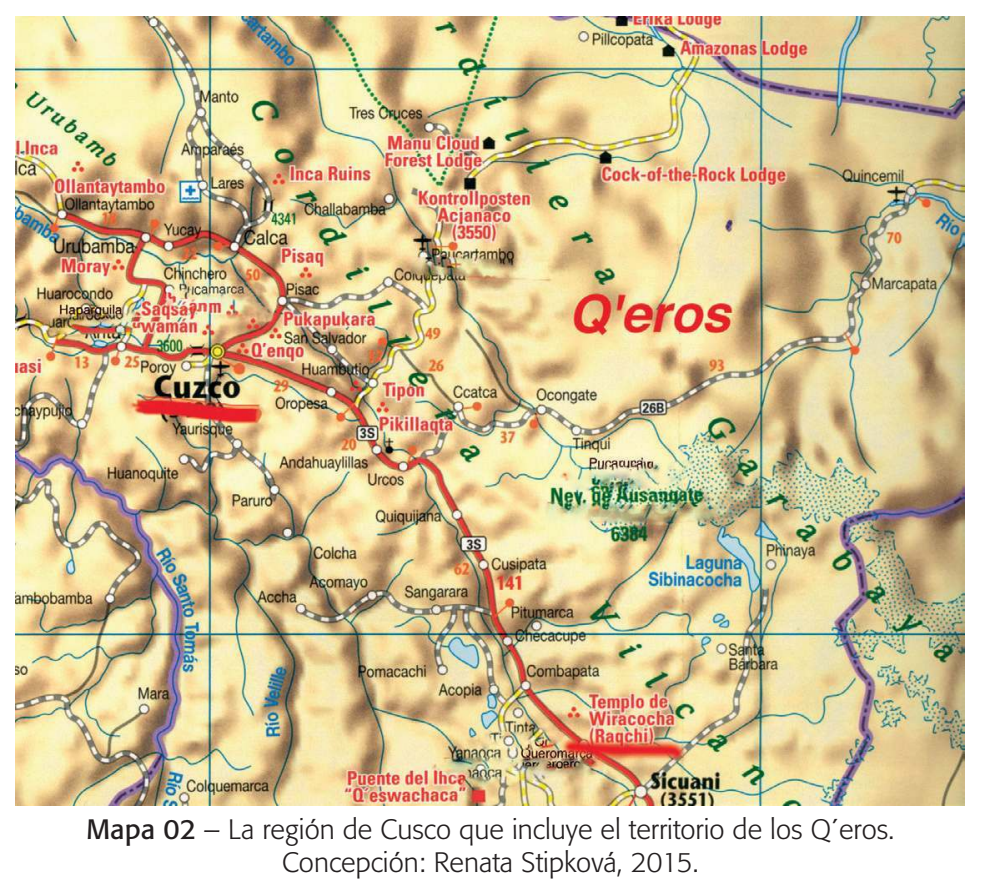

53. En un artículo de La Prensa, del 30.4.2015, se publicó la estimación del Ministerio de Economía y Finanzas en Perú acerca del crecimiento de un 5,5 \% en promedio entre 2016 y 2018, véase http://laprensa.peru.com/economia/noticia-mef-economia-crecera-55-promedio-entre-2016-2018-43385, consultado el 10.5.2015. 
Los Q'eros fueron considerados como último ayllu de los Incas. ${ }^{54} \mathrm{La}$ caminata por la zona habitada por los Q'eros duraba 6 días y se realizaba a pie en compañía de llamas o mulas que llevaban la carga y, naturalmente, en compañía de los Q'eros en cuyos pueblos uno podía ir a conocer su modo de vida. Los Q'eros llevaban una vida difícil, aprovechando los pisos ecológicos, ${ }^{55}$ para poder criar las llamas, cultivar papa (sobre $3500 \mathrm{~m}$.) y maíz (sobre 2800-3000 m.), vivían en el movimiento permanente entre los pastos y los terrenos de cultivo (la caminata desde la comunidad «alta» hasta la zona de maizales duraba varios días $\left.{ }^{56}\right)$. Habitaban casas pequeñas de piedra y techo de paja, sin ventanas. Como en las alturas no crecen los árboles, las mujeres cocinaban utilizando los excrementos secos de los animales. Los niños, desde pequeños, se dedicaban al pastoreo de llamas. Hay que comprender que los jóvenes, sobre todo, aprovecharon con satisfacción las posibilidades de traslado a las zonas templadas y, según sus opiniones, más animadas. ${ }^{57}$ Actualmente, en la zona tradicional de los Q'eros, hay pueblos completamente abandonados, en otros viven unos pocos ancianos. ${ }^{58}$ Escasos jóvenes se quedaron para continuar con el pastoreo de llamas y ovejas. Los participantes del turismo vivencial están cambiando la destinación y las actividades del turismo místico-chamánico se desarrollan en los centros de los valles o en las ciudades.

54. Según afirmaciones del antropólogo Jorge Flores Ochoa durante los cursos sobre Tradiciones Andinas, dictados en la Universidad Nacional San Antonio Abbad de Cusco, en el año 2002. Sobre la vida tradicional de los Q'eros, se puede leer el libro de Jorge Flores Ochoa y Juan Víctor Nuñez del Prado (eds.).Q'ero, el último ayllu inka, op. cit. Ayllu, en la lengua quechua, significa linaje inca, familia grande que incluye a todos los parientes. Véase también Juan Flores Ochoa y Ana María Fries, Puna, qheswa, yunga. El hombre y su medio en $Q$ 'ero, op. cit.

55. Terrazas ecológicas que se diferencian por las condiciones climáticas y vegetales de cada una de las alturas.

56. Experiencia personal.

57. Confirmaciones proporcionadas por los jóvenes becados Q'eros apoyados por la Fundación Inka entre los años 2002 y 2008. Sobre las migraciones de los campesinos en el departamento de Cusco, véase Hideo Kimura, «Los orígenes en el campo». El Qosqo, antropología de la ciudad. Hiroyasu Tomoeda, Jorge Flores Ochoa (eds.). Cuzco: Centro de Estudios Andinos / Ministerio de Educación del Japón, 1992. 61-63.

58. Experiencia personal de los viajes a Q'eros en los últimos años (2012-2014). 


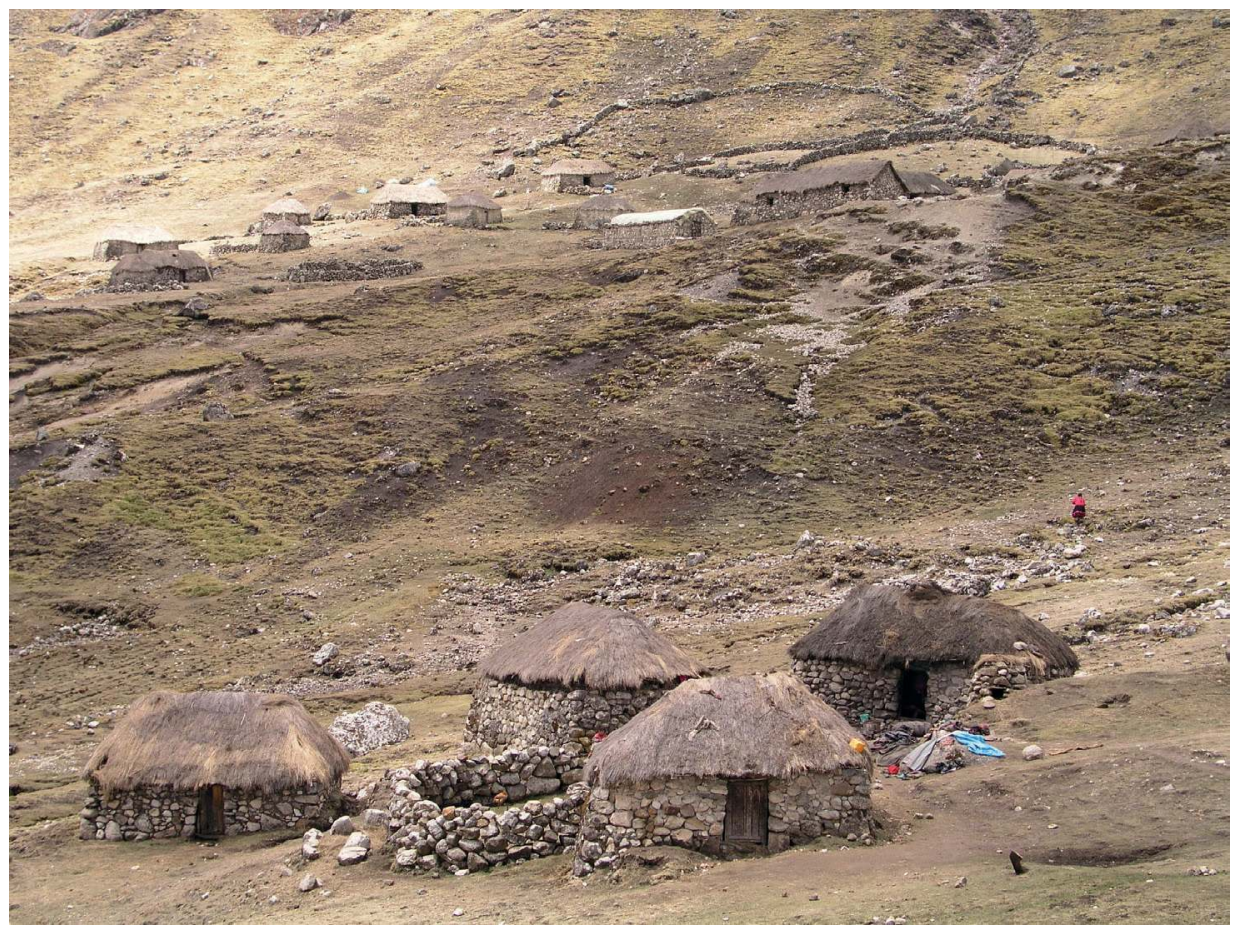

Foto 7 - Casas típicas de la zona Q'eros, 2003.

\section{Conclusión}

Gracias al crecimiento económico en Perú, y se supone su incremento para el futuro (como lo hemos indicado, el Ministerio de Economía y Finanzas presume el crecimiento de 5,5\% en promedio entre los años 2016 y 2018), el flujo de los turistas, no sólo internacionales sino también nacionales, crece constantemente ${ }^{59}$. Se puede constatar el interés de los viajeros extranjeros, tanto como de los nacionales, por el turismo vivencial en el país, incluyendo las regiones de la sierra. El fenómeno está facilitado por la situación de paz y seguridad, también en el interior del país, y por el mejoramiento de la infraestructura global, sobre todo la ampliación de la red de carreteras, de las cuales -ahora, también en las zonas de las comunidades altoandinas-, muchas son asfaltadas. El gobierno peruano promueve el turismo internacional como nacional, en el país, mediante campañas, como lo hemos señalado en la primera parte de este trabajo.

59. Véase http://www.americaeconomia.com/analisis-opinion/turismo-en-el-peru-gran-oportunidad-de-desarrollo, consultado el 19.7.2015. 
Nuestra experiencia personal nos permite afirmar, por lo demás, que los comuneros aprecian el apoyo y consejos, y toman en cuenta las recomendaciones de los coordinadores de las agencias de viajes o de los coordinadores de las ONGs.

Las actividades realizadas por los turistas, en el marco del turismo vivencial, están relacionadas con los paseos por la naturaleza, los trabajos diarios en el campo, sobre todo el pastoreo de llamas y ovejas y la agricultura. El paquete turístico en los Andes, incluye alojamiento, alimentación local, demostraciones de fabricación de artesanía, participación en las fiestas y rituales, sobre todo en la ceremonia del Pago a Pachamama -a la Madre tierra.

Prevalece el impacto positivo del turismo vivencial en la vida comunal. Se trata de una actividad económica complementaria que genera el desarrollo económico y social, gracias a los ingresos financieros. Las estancias de los turistas en los pueblos incitan a los comuneros a que mejoren el ambiente en las casas alquiladas y en las comunidades, en general. El interés de los visitantes que admiran los productos de artesanía, los trajes típicos, danzas, música de la región, lengua quechua, y respetan las tradiciones, contribuye al fortalecimiento o revitalización de la identidad étnica, sobre todo entre los jóvenes.

Sin embargo, en algunos lugares (por ejemplo, en las islas Uros del lago Titicaca, en el departamento de Puno), el flujo turístico permanente y los supuestos beneficios financieros debidos al consumo de los servicios turísticos, así como las ganancias de la venta de productos, provocan un desarrollo masivo sin límites (muliplicación de las islas construidas ahora con totora y con botellas plásticas) que finalmente afecta al medio ambiente.

De acuerdo al crecimiento económico, al desarrollo también en la región de la sierra, aparecen nuevas oportunidades de trabajo en los centros distritales y regionales (en las construcciones de las carreteras y edificios, en la minería, etc.) y muchos pobladores de las zonas altoandinas bajan a los valles buscando trabajo.$^{60}$ Abandonan sus comunidades así que, en algunos lugares, se encuentran pueblos completamente vacíos o habitados apenas por unos pocos ancianos -como en el territorio de los Q'eros, en el departamento de Cusco. Antes, la zona habitada por los Q'eros era muy popular para los turistas que buscaban la aventura y el romanticismo que ofrecía el turismo vivencial en la zona, incluyendo la posibilidad de conocer la vida cotidiana de los serranos que parecía ser relicto de la época de los Incas y la sabiduría de los sacerdotes andinos -shamanes. Entonces, cuando la zona se fue despoblando, se produjo un cambio de preferencias turísticas. Las agencias de viajes que antes organizaban caminatas

60. Experiencias personales, del trabajo en 60 comunidades donde se realizan los proyectos de la Fundación Inka. 
y estancias en el territorio de los Q'eros, en el marco del turismo vivencial, como se dijo, se orientaron a otras destinaciones.

A pesar de estos ejemplos menos satisfactorios, se puede constatar que el turismo vivencial, en la mayoría de los casos, en Perú, cumple con criterios del turismo en lo que atañe a la sostenibilidad ambiental (no hay que olvidar que los serranos indígenas, en general, sienten orgullo y valoran su medio natural Madre tierra), a la sostenibilidad social -las comunidades donde se realizan los proyectos del turismo vivencial, generalmente, lograron involucrar en el programa a un gran número o a la mayoría de sus pobladores, y velan por la justa distribución de los turistas, es decir de los ingresos financieros entre los participantes del proyecto-, y a la sostenibilidad cultural -el turismo vivencial ayuda a conservar los recursos culturales, incluyendo las tradiciones espirituales.

El turismo vivencial presenta una oportunidad benéfica, tanto para los turistas que pueden enriquecerse adquiriendo conocimientos sobre la vida de los campesinos indígenas y observando o ayudando en sus labores cotidianas, descubriendo las tradiciones y aprendiendo vocabulario de la lengua local, como para los comuneros indígenas a quienes aporta ingresos financieros y experiencias sociales de la convivencia con los turistas nacionales y extranjeros.

\section{Bibliografía}

ALIAGA María Eugenia de, CABRERA NIERI Rodrigo, CARBAJAL BARREDA Omar. Capacitación en estándares de calidad y buenas prácticas de turismo sostenible. Lima: Universidad Antonio Ruiz de Montoya/Asociación Odebrecht Perú, abril de 2011, 19 p., disponible en http://www.google.cz/url?sa= $\mathrm{t} \& \mathrm{rct}=\mathrm{j} \& \mathrm{q}=\& \mathrm{esrc}=\mathrm{s} \&$ source $=$ web $\& \mathrm{~cd}=8 \& \mathrm{ved}=0 \mathrm{CFoQFjAH} \& u r l=\mathrm{http} \% 3 \mathrm{~A} \%$ 2F\%2Fwww.isur.org.pe\%2Fpublicaciones\%2Fdescarga\%2F49\&ei=ZTNOVeK yI8z5Uoa_gcAE\&usg=AFQjCNHxnxfPEDdY59Uasaz3CaxyJu3iyw, consulta del 1.5.2015.

ALLEN Catherina J. La coca sabe. Coca e identidad cultural en una comunidad andina. Cuzco: Centro Bartolomé de las Casas, 2008, 372 p.

ASCENCIÓN UGARTE Felix.Turismo sostenible en el Perú. Planificación, gestión y desarrollo. Lima: Universidad Ricardo Palma, 2005, 260 p.

CONRADY Roland, BUCK Martin, VIEHL Pia. Trends and Issues in Global Turism 2012. Berlin: Springer, 2012, 273 p.

CUSIHUAMAN Antonio [1976]. Diccionario quechua. Cusco-Collao. Cuzco: Centro Bartolomé de las Casas, 2001.

DÁVILA GARCÍA Bruno, ZLATER LOMELLINI Dusan, ZLATTER CASTRAT Igor. Ecoturismo competitivo: propuesta para su implementación en Madre 
de Díos. Lima: Pontificia Universidad Católica del Perú - Fondo editorial, 2005, $264 \mathrm{p}$.

FLORES OCHOA Jorge, FRIES Ana María (eds). Puna, qheswa, yunga. El hombre y su medio en Q'ero.Lima:Banco Central de Reserva del Perú, 1989. 85 p.

FLORES OCHOA Jorge, NUÑEZ DEL PRADO Juan Víctor (eds). Q'ero, el último ayllu inka. Cusco: Centro de Estudios Andinos, 1983, 230 p.

FORET Miroslav. Cestovní ruch v regionálním rozvoji (El turismo en el desarrollo regional). Brno: Mendelova univerzita, 2013, 137 p.

FULLER OSORES Norma. Turismo y cultura. Entre el entusiasmo y el recelo. Lima: Pontificia Universidad Católica del Perú - Fondo editorial, 2014, 140 p.

KIMURA Hideo, "Los orígenes en el campo». El Qosqo, antropología de la ciudad. Hiroyasu Tomoeda, Jorge Flores Ochoa (eds.). Cuzco: Centro de Estudios Andinos/Ministerio de Educación del Japón, 1992. 61-63.

NEIRA Hugo. Hacia la Tercera Mitad. Perú XVI-XX. Lima: Editorial Herética, 2005.

RODRÍGUEZ ARQUE René. Raqchi, maravilloso y majestuoso parque arqueológico, Cuzco: Inetgraff, sin año de publicación. 28 p.

ROSTWOROVSKI DE DIEZ CANSECO María (1999). Historia del Tahuantinsuyo. Lima: Instituto de Estudios Peruanos, 2013.

ROZAS Washington. «Los Paqo en Q'ero». Q'ero, el último ayllu inka. Jorge Flores Ochoa, Juan Víctor Nuñez del Prado (eds.). Cuzco: Centro de Estudios Andinos, 1983, 143-158.

s.a. «Puno: islas del Titicaca recibirán electricidad para impulsar turismo». El Comercio (28 de agosto de 2012); disponible en http://elcomercio.pe/vamos/ peru/puno-islas-titicaca-recibiran-electricidad-impulsaran-turismo-noticia-1462137, consultado el 25.8.2014.

VILÍMKOVÁ Olga. Základy jazyka quechua, učebnice pro samouky.(Quechua básico, manual para autodidactas). Praga: Universidad de Economía-Oeconomica, 2005.

VILÍMKOVÁ Olga. Turismo con especial referencia a América Latina, Praga: Smart Press, 2011. 191 p.

VIGNA Anne. «Un moyen de sauver les villages». Le monde diplomatique (julio de 2006); disponible en www.monde-diplomatique.fr/2006/07/VIGNA/13609, consultado el 20.3.2008.

VIVANCE ARANA Rafael, YLLANES CHOQUE José. Historia. Compendio Académico, tomo 2. Cuzco: Academia Raimondi, 2006.

WEBSTER Steven, «El pastoreo en Q'ero». Q'ero, el último ayllu inka. Jorge Flores Ochoa, Juan Víctor Nuñez del Prado (eds.). Cuzco: Centro de Estudios Andinos, 1983. 53-80. 
Resumen: El artículo presenta la situación en el campo del turismo vivencial en los Andes del Perú. Se constata el desarrollo y popularidad creciente de ello entre todas las partes presentes en el asunto: campesinos, turistas y mediadores (o sea agencias turísticas). Se puede afirmar que el impacto del turismo participativo en la vida comunal y en el medio ambiente son generalmente positivos. El turismo activa las economías locales y contribuye en mejorar las condiciones de vida de las poblaciones beneficiadas. Las experiencias de intercambios culturales y el respeto presentado por los extranjeros a las tradiciones andinas influyen en la percepción de su misma cultura por parte de la juventud local. Así, el turismo participativo contribuye en el fortalecimiento de la identidad cultural. Sin embargo, hay que tener en cuenta los riesgos que presenta el flujo turístico exageradamente aprovechado por algunos pobladores que -sin pensar en el futuro- pueden, por sus actividades no controladas, dañar considerablemente el medio ambiente.

Palabras clave: Perú, turismo vivencial, desarrollo de las comunidades andinas, revitalización de identidad étnica.

Résumé : L'article décrit la situation dans le domaine du tourisme collaboratif dans les Andes péruviennes. On constate une popularité et un développement croissants de l'écotourisme auprès de toutes les parties prenantes : populations rurales, touristes et médiateurs (agences touristiques). On constate, également, que l'impact de l'écotourisme sur la vie des villages et communautés, ainsi que sur l'environnement, est, en général, positif. Le tourisme encourage l'économie locale, contribue à améliorer les conditions de vie de la population concernée. Les expériences de l'échange culturel et du respect dont font preuve les étrangers vis-à-vis des traditions andines influencent la perception de sa propre culture par la jeunesse locale. Le tourisme participatif contribue, ainsi, à la revitalisation de l'identité ethnique. Cependant, il faut prendre conscience des risques éventuels provoqués par un flot de touristes, et de l'exploitation excessive de l'écotourisme par certaines populations rurales dont les activités, non contrôlées, peuvent nuire considérablement à l'environnement.

Mots-clefs : Pérou, tourisme collaboratif, développement des communautés andines, revitalisation de l'identité ethnique.

Biografía: Olga Vilímková es profesora titular en la Facultad de Relaciones Internacionales de la Universidad de Economía de Praga, República Checa. Defendió una tesis de doctorado titulada Guatemala: conflicto armado (1960-1996) y situación actual con especial referencia a los mayas, Facultad de Filosofía y Letras, Universidad Carolina, Praga, 2009, 360 p., publicada en checo por Smart Press, Praga, 2013. Ha sido profesora invitada en el Lateinamerika Institut de Viena, en 2005, donde impartió el curso semestral titulado "Lengua y civilización quechua en los Andes peruanos". Es fundadora y presidenta de la Fundación Inka (con sede en Praga) que, desde 2002, apoya a los estudiantes talentosos, los proyectos de desarrollo en las comunidades andinas en Perú y las organizaciones mayas en Guatemala. Es vice-presidenta de la Sociedad Checo-iberoamericana. Es también guía turística para América Latina, autora de varios libros, exposiciones, programas de televisión y radio sobre la vida de los indígenas, sus costumbres y tradiciones.

Biographie : Olga Vilímková est maître de conférence au Département d'Études des Relations Internationales de I'Université d'Economie de Prague, République Tchèque. Elle a soutenu une thèse de doctorat intitulée Guatemala: conflicto armado (1960-1996) y situación actual con especial referencia a los mayas, à la Faculté de Lettres de I'Université Charles de Prague en 2009, une thèse qui a été publiée en tchèque (Prague, Smart Press, 2013, 360 p.). Elle a été professeure invitée du Lateinamerika Institut de Vienne, en 2005, où elle a assuré le cours semestriel intitulé "Langue et civilisation quechua dans les Andes péruviennes". Elle est fondatrice et présidente de la Fondation Inka (dont le siège est à Prague) qui, depuis 2002, soutient des étudiants méritants, des projets de développement dans les villages andins au Pérou et des organisations mayas au Guatemala. Elle est vice-présidente de la Société Tchéco-iberoaméricaine. Elle est, également, guide touristique pour l'Amérique latine, auteure de plusieurs livres et expositions, réalisatrice d'émissions de télévision et de radio sur la vie des Indiens au Pérou et au Guatemala, leurs coutumes et traditions. 